\title{
A Time-Resolved Study on the Reactivity of Alcoholic Drinks with the Hydroxyl Radical
}

\author{
Gemma M. Rodriguez-Muñiz ${ }^{(\mathbb{C}}$, Miguel A. Miranda * and M. Luisa Marin *(1) \\ Instituto de Tecnología Química, Universitat Politècnica de València-Consejo Superior de Investigaciones \\ Científicas, Avda. de los Naranjos s/n, E-46022 Valencia, Spain; gemrodmu@itq.upv.es \\ * Correspondence: mmiranda@qim.upv.es (M.A.M.); marmarin@qim.upv.es (M.L.M.); \\ Tel.: +34-963877815 (M.L.M.)
}

Received: 2 December 2018; Accepted: 7 January 2019; Published: 10 January 2019

\begin{abstract}
Reactive oxygen species (ROS) can provoke damage to cells, where their concentrations are regulated by antioxidants. As the hydroxyl radical $(\bullet \mathrm{OH})$ is the most oxidizing ROS, we have focused our attention on the use of a mechanistically based time-resolved methodology, such as laser flash photolysis, to determine the relative reactivity of alcoholic beverages towards $\bullet \mathrm{OH}$ as an indicator of their antioxidant potential. The selected drinks were of two different origins: (i) those derived from grapes such as red wine, white wine, white vermouth, marc and brandy and (ii) spirits not derived from grapes: triple sec, gin, whisky, and rum. Initially, we determined the quenching rate constant of ethanol with $\bullet \mathrm{OH}$ and then we explored the reactivity of the different beverages, which was higher than expected based on their alcoholic content. This can be attributed to the presence of antioxidants and was especially remarkable for the grape-derived drinks.
\end{abstract}

Keywords: antioxidants; laser flash photolysis; spirits; transient absorption; wine

\section{Introduction}

Molecular oxygen is crucial for living beings; however, there are several highly reactive, oxygen-derived chemical entities that can provoke damage to cells. Among them, reactive oxygen species (ROS) include superoxide radical anion $\left(\mathrm{O}_{2}{ }^{\bullet-}\right)$, hydroxyl radical $(\bullet \mathrm{OH})$ and singlet oxygen $\left({ }^{1} \mathrm{O}_{2}\right)$ [1]. The hydroxyl radical is by far the most potent oxidizing ROS, with a redox potential of $+2.33 \mathrm{~V}$ (vs normal hydrogen electrode, NHE) [2]. It is capable of reacting with a variety of molecules through three main mechanisms: $\mathrm{H}$-abstraction, addition to double bonds or aromatic rings, and electron transfer, in all cases with high reaction rate constants (in the order of $10^{9}-10^{10} \mathrm{M}^{-1} \mathrm{~s}^{-1}$ ) [3]. It has a very short lifetime (in the range of ns to $\mu \mathrm{s}$ ) [4]; therefore, its steady-state concentration is extremely low $\left(10^{-15}\right.$ to $\left.10^{-18} \mathrm{M}\right)$ [5]. Nevertheless, it has been claimed as the main species responsible for the oxidative damage to biomolecules [6]. However, this hypothesis is currently under revision, and some authors have provided evidence on some beneficial roles of ROS, acting, for instance, as cellular signaling entities $[7,8]$.

The concentration of ROS in cells is regulated by enzymatic and non-enzymatic antioxidant systems. Unbalance between excessive concentration of ROS and low levels of antioxidants causes oxidative stress, which has been related to age-related disorders, cancer, cardiovascular, inflammatory, and neurodegenerative diseases [9-11].

Examples of non-enzymatic antioxidants include glutathione, vitamin $C$ and $\alpha$-tocopherol. More recently, carotenoids and flavonoids, a huge and diverse group of secondary plant metabolites, have merited attention as natural antioxidants [12-19]. In fact, flavonoids together with other polyphenols or anthocyanins, all components of grape-based drinks, have been related to the prevention of coronary heart disease (CHD), giving rise to the so-called "French paradox" due to the low incidence of mortality 
associated to CHD in France despite the high intake of saturated fat [20]. The antioxidant activity of phenolic compounds contained in grapes and red wines has been confirmed based on the inhibition of lipid peroxidation experiments [21].

The relationship between the antioxidant activity of drinks and foods and their flavonoids content is complex, due to the great structural variety of flavonoids and their metabolites along with the diverse mechanisms of action of the different ROS. Furthermore, the antioxidant activity results depend on the method used, essentially chemically or biologically based [13,22,23].

Herein, we will focus our attention on $\bullet \mathrm{OH}$, not only because it is the most reactive ROS, but also because it is a model radical that combines all the possible reaction pathways of these reactive intermediates (hydrogen abstraction, addition to unsaturated moieties, electron transfer, etc.). We propose an approach to determine its reactivity, with a variety of drinks with time-resolved precision. The methodology, based on laser flash photolysis (LFP) measurements, was initially developed by Platz et al. with aromatic hydrocarbons [24,25]. Later, we optimized the methodology to determine the reactivity of $\bullet \mathrm{OH}$ with drugs and pesticides of environmental concern, or nucleosides in lipophilic media $[4,26,27]$. However, in spite of the potential of time-resolved techniques to determine reaction rate constants for mechanistic pathways, even in complex systems, such an approach has not been explored yet to rationalize the antioxidant activity of foods or beverages.

The selected drinks are commercially available and can be classified into two different groups depending on their origin: (i) those derived from grapes and (ii) spirits not derived from grapes. Selected samples for the first group were Rioja Lagunilla (red wine), Marina Alta (white wine), Martini Bianco (white vermouth), Orujo Ruavieja (marc) and Carlos III (brandy). Selected samples for the second group were Cointreau (triple sec), Ginebra Larios (gin), Ballantines (whisky) and Ron Negrita (rum).

\section{Results and Discussion}

The hydroxyl radical was cleanly obtained from the homolytic rupture of $\mathrm{N}$-hydroxypyridine2(1H)-thione (NPT) upon laser flash photolysis at $355 \mathrm{~nm}$. As a result of this homolytic rupture, the "invisible" hydroxyl radical is generated together with the unreactive pyrithiyl radical that has an absorption maximum at $490 \mathrm{~nm}$, and therefore provides evidence for the process (Scheme 1 top). To reveal the hydroxyl radical, trans-stilbene (TS) was used as a trap giving rise to a detectable adduct (TS-OH•) with a characteristic transient absorption band with maximum at ca. $390 \mathrm{~nm}$ (Scheme 1 middle).

1) Generation of $\cdot \mathrm{OH}$

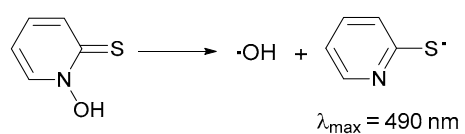

2) Trapping and detection of $\cdot \mathrm{OH}$

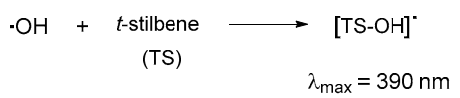

3) Competing Experiments

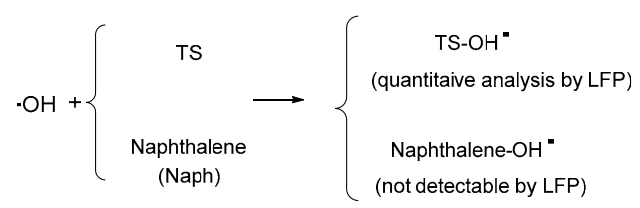

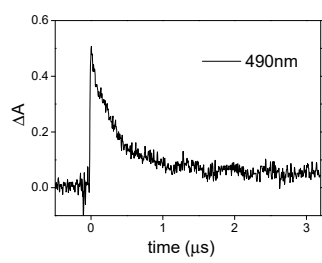
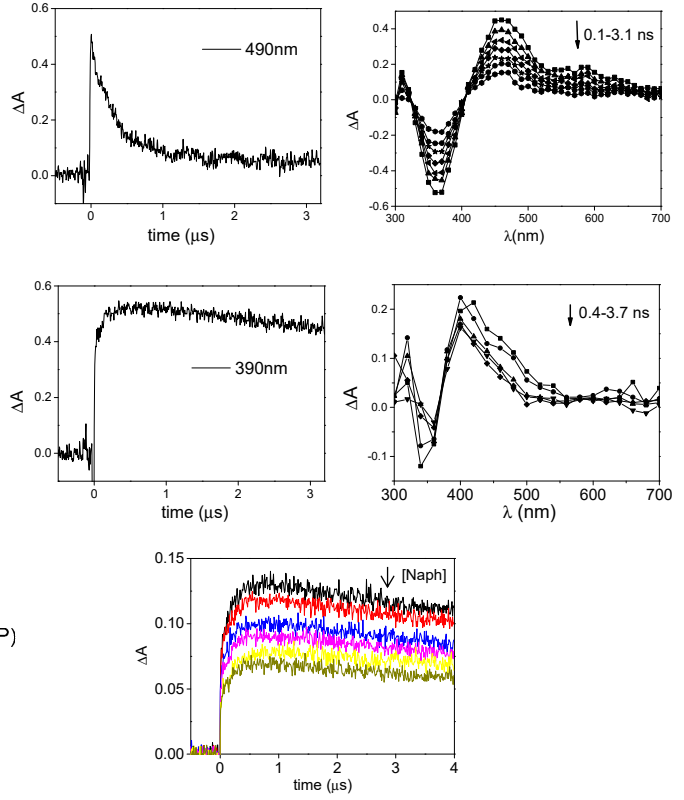

Scheme 1. Experimental generation of the hydroxyl radical, trapping with trans-stilbene and competitive analysis in the presence of naphthalene. 
In the optimized protocol, the kinetic traces at $390 \mathrm{~nm}$ were plotted in the absence and with the increasing concentration of naphthalene (Naph), of known quenching rate constant with the hydroxyl radical $\left(k_{q}=1.8 \times 10^{9} \mathrm{M}^{-1} \mathrm{~s}^{-1}\right)$ [25]. A Stern-Volmer competitive analysis $\left(\Delta \mathrm{A}_{\mathrm{o}} / \Delta \mathrm{A}_{\mathrm{x}}\right.$ versus $\left.\mathrm{C}_{\mathrm{x}}\right)$, in which $\mathrm{A}_{\mathrm{o}}$ and $\mathrm{A}_{\mathrm{x}}$ represent the initial absorbance of the TS-OH• at $390 \mathrm{~nm}$ in the absence and at every " $x$ " concentration of naphthalene, provided the response of the technique, that was subsequently used as standard (Scheme 1 bottom).

Since ethanol is the common ingredient to all the beverages, we initially ran the protocol using ethanol to find its quenching rate constant versus the hydroxyl radical, using naphthalene as standard (Figure 1A). We plotted the transient absorption trace at $390 \mathrm{~nm}$ in the absence and in the presence of different concentrations of naphthalene and, in parallel, we recorded the same trace in the presence of increasing concentrations of ethanol. In both cases, $\Delta A_{o} / \Delta A_{x}$ were plotted versus $C_{x}$ and fitted to a straight line:

$$
\begin{gathered}
\left(\Delta \mathrm{A}_{\mathrm{o}} / \Delta \mathrm{A}_{\mathrm{x}}\right)_{\text {Naph }}=(0.97 \pm 0.03)+(21.11 \pm 1.33) \mathrm{C}_{\text {Naph }}, \mathrm{r}^{2}=0.98 \\
\left(\Delta \mathrm{A}_{\mathrm{o}} / \Delta \mathrm{A}_{\mathrm{x}}\right)_{\text {ethanol }}=(0.96 \pm 0.08)+(1.65 \pm 0.07) \mathrm{C}_{\text {ethanol }}, \mathrm{r}^{2}=0.99
\end{gathered}
$$

From the slopes of the two straight lines $\left(\Delta A_{0} / \Delta A_{x}\right.$ versus $\left.C_{x}\right)$, we determined the quenching rate constant of ethanol with the hydroxyl radical which was found to be $1.41 \times 10^{8} \mathrm{M}^{-1} \mathrm{~s}^{-1}$ (Figure 1B), one order of magnitude lower than that of naphthalene, but in reasonable agreement with the reported value $\left(8.28 \times 10^{7} \mathrm{M}^{-1} \mathrm{~s}^{-1}\right)[28]$.

(A)

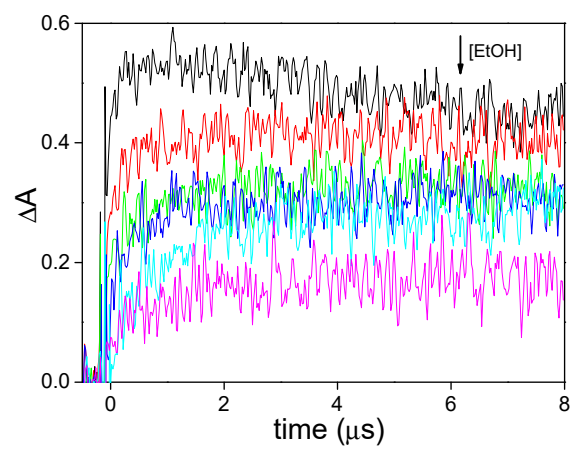

(B)

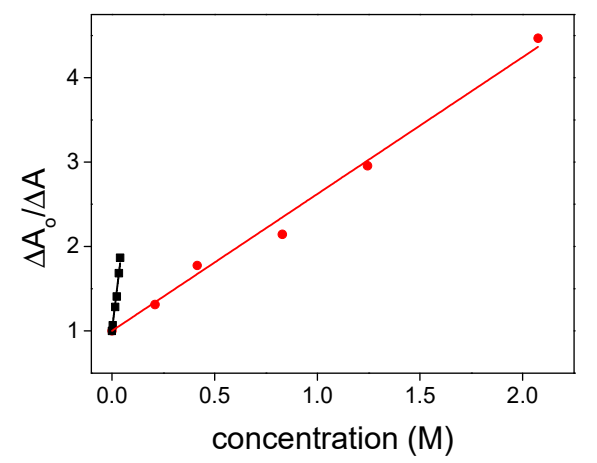

Figure 1. (A) Kinetic traces recorded at $390 \mathrm{~nm}$ after laser flash photolysis irradiation $\left(\lambda_{\mathrm{exc}}=355 \mathrm{~nm}\right.$ ) of deaerated acetonitrile solutions of $N$-hydroxypyridine-2(1H)-thione (NPT) $(0.29 \mathrm{mM})$ and trans-stilbene (TS) (7.5 mM) with increasing concentrations of ethanol (0-2.075 M); (B) Corresponding Stern-Volmer plots obtained as the ratio $\Delta \mathrm{A}_{\mathrm{o}} / \Delta \mathrm{A}_{\mathrm{x}}$ versus $\mathrm{C}_{\mathrm{x}}$ for Naph (0-0.05 M, black squares) and ethanol (0-2.075 M, red circles). (The values used in the case of Naph were taken from the graph of Scheme 1 bottom).

Next, we explored the reactivity of the different drinks against the hydroxyl radical following this protocol and compared their reactivity to the one of pure ethanol. Thus, to test the overall reactivity of the beverages against the hydroxyl radical, increasing volumes of every beverage (from 0 to $0.5 \mathrm{~mL}$ ) were added to a $2.4 \mathrm{~mL}$ acetonitrile solution of NPT + TS and the total volume was completed up to $4 \mathrm{~mL}$ using acetonitrile (Figure 2). Acetonitrile was selected to perform the photophysical experiments because it exhibits a low reactivity towards $\bullet \mathrm{OH}\left(k \mathrm{ca} .10^{6} \mathrm{M}^{-1} \mathrm{~s}^{-1}\right)$ [24]. Although, in all cases, quenching was unambiguously noticed, it did not happen to the same extent for all the drinks. Observing this figure, the beverages can clearly be divided into two groups. The first group contained red wine, white wine, white vermouth, marc and brandy (all derived from grapes) which show higher reactivity than the second group of spirits (triple sec, gin, whisky and rum-all from origins different from grapes). Next, we plotted $\Delta \mathrm{A}_{\mathrm{o}} / \Delta \mathrm{A}_{\mathrm{x}}$ versus $\mathrm{V}_{\mathrm{x}}$, (Figure 3 ) and in all cases, the obtained values fitted to a straight line (not shown). Not surprisingly, red wine exhibited the highest reactivity. From the ratio between the slope of the corresponding fittings and that of ethanol, we found the relative quenching rate constants 
for the beverages against $\bullet \mathrm{OH}$ (Table 1 ). According to the determined values, the relative quenching rate constants for beverages of grape origin were higher than 1 , while those from a different origin had a relative quenching constant lower than 1 . On the contrary, the group of grape-derived beverages had lower ethanol content than the group of spirits, although the correlation between ethanol content and quenching values is not straightforward in every case. In fact, even in the case of the second group of spirits, the reactivity with $\bullet \mathrm{OH}$ was higher than expected based on the alcoholic content, probably due to the presence of constituents extracted from the woody barrels.

(A)

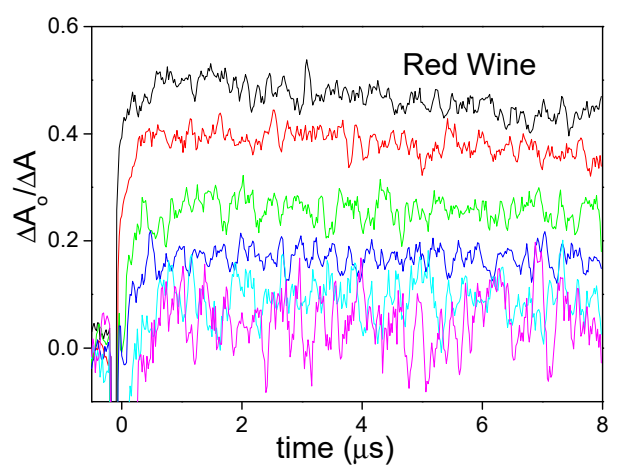

(C)

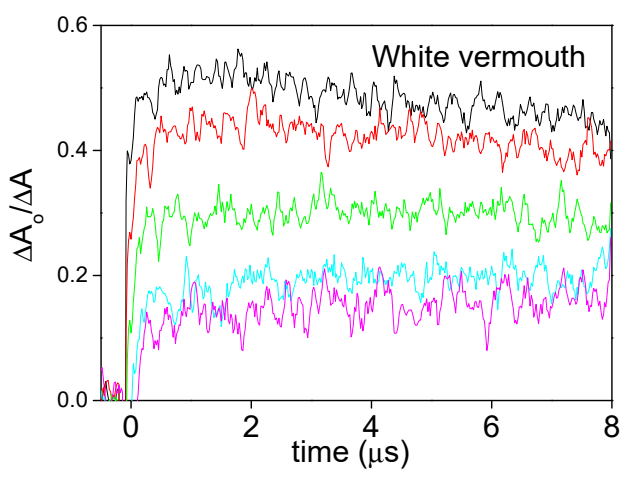

(E)

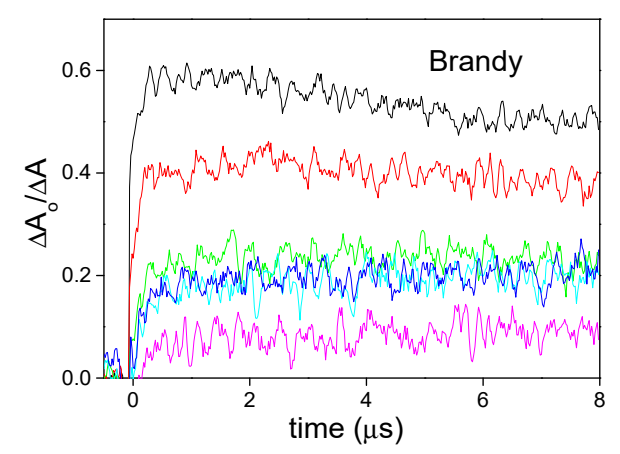

(B)

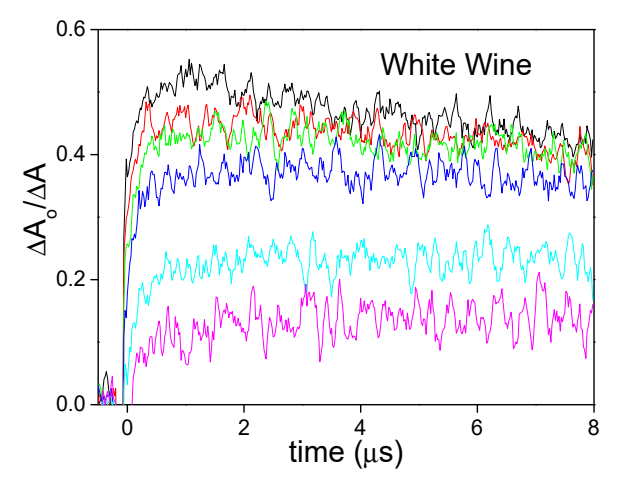

(D)

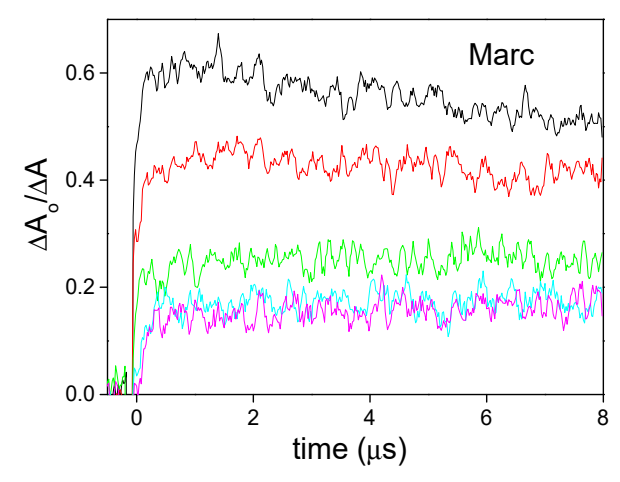

(F)

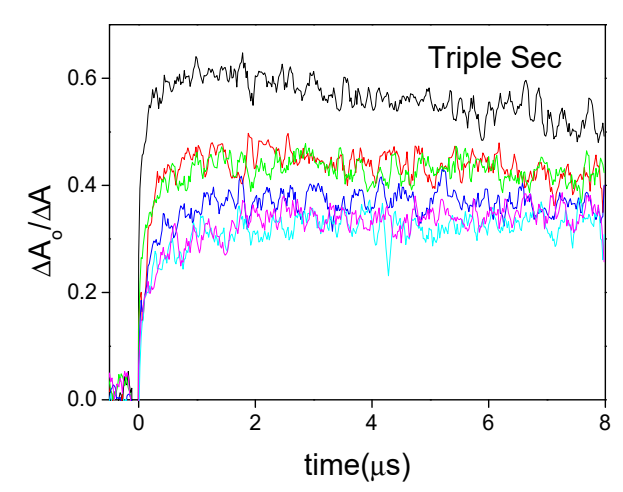

Figure 2. Cont. 
(G)

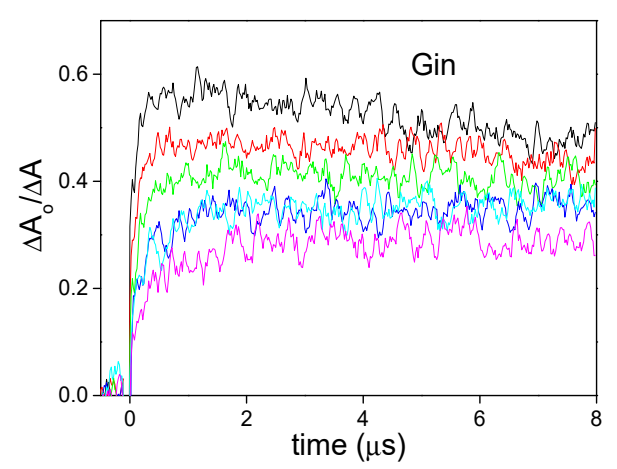

(H)

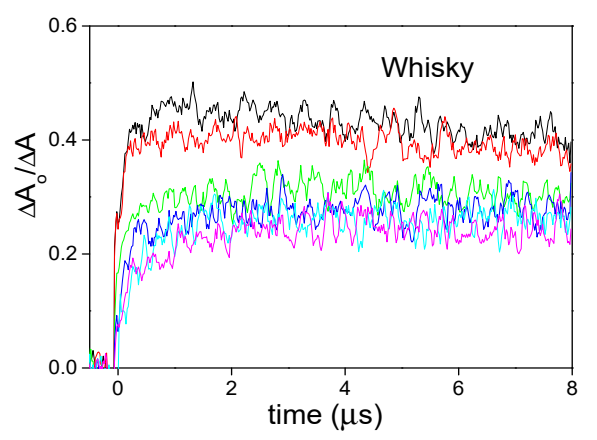

(I)

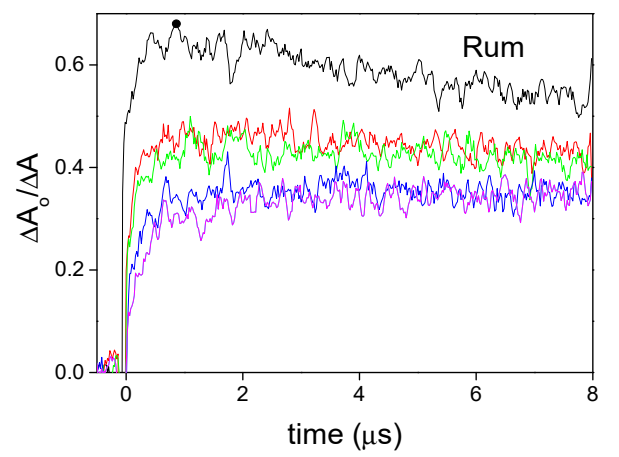

Figure 2. Kinetic traces recorded at $390 \mathrm{~nm}$ after laser flash photolysis irradiation $\left(\lambda_{\mathrm{exc}}=355 \mathrm{~nm}\right)$ of deaerated acetonitrile solutions of NPT $(0.29 \mathrm{mM})$ and TS $(7.5 \mathrm{mM})$ with increasing volumes of beverages $(0-0.5 \mathrm{~mL})$ : red wine $(\mathbf{A})$, white wine $(\mathbf{B})$, white vermouth $(\mathbf{C})$, marc $(\mathbf{D})$, brandy $(\mathbf{E})$, triple $\sec (\mathbf{F})$, gin $(\mathbf{G})$, whisky $(\mathbf{H})$, and $\operatorname{rum}(\mathbf{I})$.

(A)

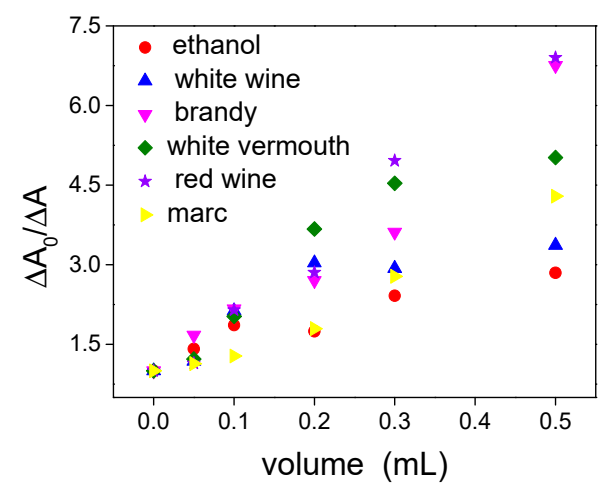

(B)

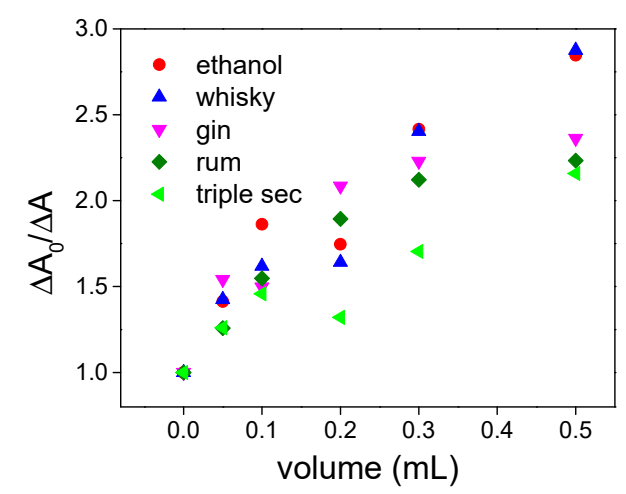

Figure 3. Stern-Volmer-like plots obtained as the ratio $\Delta \mathrm{A}_{\mathrm{O}} / \Delta \mathrm{A}_{\mathrm{x}}$ versus added volume of the different beverages (values taken from Figure 2). (A) drinks derived from grapes; (B) distillates non-derived from grapes. 
Table 1. Quenching rate constants for the beverages against the hydroxyl radical $(\bullet \mathrm{OH})$ relative to ethanol.

\begin{tabular}{ccc}
\hline Beverage & Relative $\boldsymbol{k}_{\mathrm{OH} .}$ & Relative Ethanol Content \\
\hline Ethanol $^{\text {B }}$ & 1 & 1 \\
Red wine $^{\mathrm{a}}$ & 2.89 & 0.13 \\
White wine $^{\mathrm{b}}$ & 1.42 & 0.12 \\
White vermouth $^{\mathrm{c}}$ & 2.17 & 0.15 \\
Marc $^{\mathrm{d}}$ & 1.47 & 0.30 \\
Brandy $^{\mathrm{e}}$ & 2.61 & 0.36 \\
Triple sec $^{\mathrm{f}}$ & 0.58 & 0.40 \\
Gin $^{\mathrm{g}}$ & 0.86 & 0.38 \\
Whisky $^{\text {h }}$ & 0.97 & 0.40 \\
Rum $^{\mathrm{i}}$ & 0.75 & 0.37
\end{tabular}

a red wine: Rioja Lagunilla; ${ }^{\mathrm{b}}$ white wine: Marina Alta; ${ }^{\mathrm{c}}$ white vermouth: Martini Bianco; ${ }^{\mathrm{d}}$ marc: Orujo Ruavieja; ${ }^{\mathrm{e}}$ brandy: Carlos III; ${ }^{\mathrm{f}}$ triple sec: Cointreau; ${ }^{\mathrm{g}}$ gin: Ginebra Larios; ${ }^{\mathrm{h}}$ whisky: Ballantines; ${ }^{\mathrm{I}}$ rum: Ron Negrita.

Moreover, we intended to test the antioxidant capability of fresh grapes to investigate whether non-alcoholic derived juices had even higher quenching rate constants. For this purpose, we squeezed red and white grapes and tested the fresh juice following the optimized protocol (Figure 4). The obtained values ( 0.65 and 0.56 , respectively, relative to ethanol) indicated that the reactivity of grape juices (red and white) with $\bullet \mathrm{OH}$ is basically independent from the color of grapes and lower than that of white and red wines. This is not unexpected, as it is known that some highly active antioxidants are generated during the fermentation process.

(A)

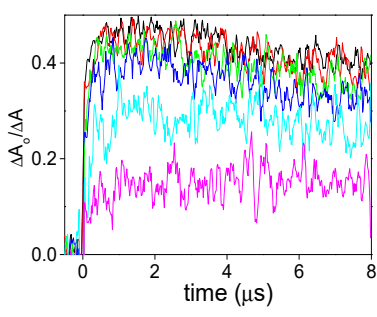

(B)

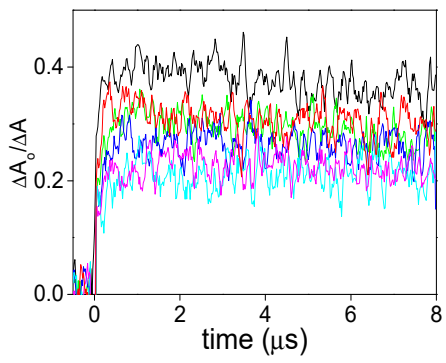

(C)

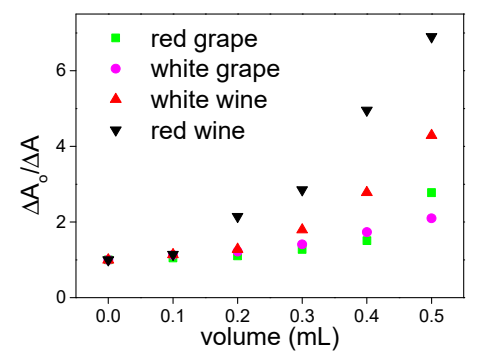

Figure 4. Kinetic traces recorded at $390 \mathrm{~nm}$ after laser flash photolysis irradiation $\left(\lambda_{\text {exc }}=355 \mathrm{~nm}\right)$ of deaerated acetonitrile solutions of NPT $(0.29 \mathrm{mM})$ and TS $(7.5 \mathrm{mM})$ with increasing volumes of freshly squeezed juice $(0-0.5 \mathrm{~mL})$ : commercial red grapes of Monastrell variety $(\mathbf{A})$, commercial white grapes of Rosseti variety (B). (C) Corresponding Stern-Volmer plots.

These results obtained from grapes indicate that there is a significant contribution from ingredients different from ethanol to the overall quenching. Among them, natural sugars, and phenolic derivatives such as flavonoids, acids, esters or terpenes could be responsible for this activity [29]. After fermentation, the group of beverages of grape origin still contained, in part, these additional components that also exhibit high reactivity against the hydroxyl radical. In addition, other alcohols are secondary derivatives from the fermentation of natural sugars, such as glycerin, propanol, sorbitol, or flavonoids. The distillation of grapes, as in the case of brandy, results in a lower content of the volatile species that is partially balanced with the higher amount of ethanol [30-34]. In the other spirits, the lower quenching rate constants can safely be attributed to the absence of this variety of minor components with antioxidant activity.

The antioxidant activity of red wine has been mainly attributed to resveratrol [34-36]. Its chemical structure related to that of trans-stilbene is susceptible to reacting with the hydroxyl radical. In fact, upon addition to resveratrol, a new signal centered at 390-420 $\mathrm{nm}$ has been described [37]. When we tested resveratrol as a quencher of the hydroxyl radical under our protocol, we observed an 
increase in absorbance at $390 \mathrm{~nm}$, which is due to the competence between TS and resveratrol for the $\bullet \mathrm{OH}$, resulting, in the second case, in an adduct that has a higher molar absorption coefficient at that wavelength (Supplementary Materials). Therefore, the reactivity of red wine against $\bullet \mathrm{OH}$ would be even higher than the experimentally determined one if the effect of resveratrol contained in it could be taken into account.

\section{Materials and Methods}

\subsection{Chemicals and Other Reagents}

Naphthalene, t-stilbene (TS), N-hydroxypyridine-2(1H)-thione (NPT) and resveratrol were obtained from Aldrich. Water was milliQ ${ }^{\circledR}$ (Merck, Darmstadt, Germany), ethanol and acetonitrile were HPLC grade. The drinks were of commercial origin. Red and white grapes were from Monastrell and Rosetti varieties, respectively. They were bought in a food store in Valencia (Spain) in September 2017.

\subsection{Photophysical Instrumentation}

Time-resolved kinetic analyses were performed using a laser flash photolysis (LFP) system equipped with a Nd:YAG SL404G-10 Spectron Laser (Lotis Tii, Minsk, Belarus) at the excitation wavelength of $355 \mathrm{~nm}$. The single pulses were of ca. $10 \mathrm{~ns}$ duration, and the energy was lower than $30 \mathrm{~mJ}$ per pulse. The detecting light source was a pulsed Lo255 Oriel Xenon lamp (Newport, Irvine, CA, USA). In addition to the laser, the system included a 77,200 Oriel monochromator, a photomultiplier (Oriel, model 70705PMT) system and a TDS-640A Tektronix oscilloscope (Bertashire, UK). A customized Luzchem Research LFP-111 system was employed to collect and transfer the output signal from the oscilloscope to a personal computer to process the data. A quartz cell of $1 \mathrm{~cm}$ optical path length was employed for all kinetic measurements, which were run at room temperature in degassed mixtures of acetonitrile-milliQ ${ }^{\circledR}$ water.

\subsection{Kinetic Experiments}

The kinetic experiments were performed in a set of quartz cuvettes as follows: to $1.2 \mathrm{~mL}$ of NPT (from a $0.48 \mathrm{mM}$ stock solution) and $1.2 \mathrm{~mL}$ of TS (from a $12.5 \mathrm{mM}$ stock solution) in deaerated acetonitrile, increasing volumes of naphthalene (from a $206 \mathrm{mM}$ stock solution), resveratrol (from a $16 \mathrm{mM}$ stock solution), ethanol, beverages or freshly squeezed grape juice were added, and the final volume was adjusted to $4 \mathrm{~mL}$. The final concentrations of NPT and TS in the cuvettes were $2.9 \times$ $10^{-4} \mathrm{M}$ and $7.5 \times 10^{-3} \mathrm{M}$, respectively. The corresponding Stern-Volmer plots were obtained from the signal due to the adduct between TS and $\bullet \mathrm{OH}\left(\lambda_{\max }=390 \mathrm{~nm}\right)\left(\mathrm{A}_{\mathrm{o}} / \mathrm{A}_{\mathrm{x}}\right)$ versus the final concentration or the final volume of the liquid added $\left(\mathrm{V}_{\mathrm{x}}\right)$.

\section{Conclusions}

The antioxidant properties of beverages and drinks are highly valuable, because they may help to decrease the oxidative stress, thereby preventing or delaying the appearance of a number of diseases. One of the most aggressive reactive oxygen species is the hydroxyl radical, because it reacts with biomolecules (and in general with organic compounds) extremely fast. In the present work, we have followed a mechanistically based time-resolved methodology to determine the relative reactivity of several alcoholic beverages towards the hydroxyl radical as an indicator of their antioxidant potential. In general, it has been shown that all the beverages exhibit a higher than expected reactivity towards the hydroxyl radical based on their alcoholic content, which can be attributed to the presence of minor amounts of components with antioxidant properties. This is especially remarkable for the grape-derived drinks, with a partial loss of the active components associated with steam distillation. In fact, grape juice reacts with the hydroxyl radical at significant rates, albeit lower than those measured for wines and spirits. The obtained results point to the suitability of the time-resolved methodology 
employed in the present work to investigate the antioxidant activity of a wide variety of foods, beverages and agriculture products.

Supplementary Materials: The following are available online. Figure S1: (A) Kinetic traces recorded at $390 \mathrm{~nm}$ after laser flash photolysis irradiation $\left(\lambda_{\text {exc }}=355 \mathrm{~nm}\right)$ of deaerated acetonitrile solutions of NPT $(0.29 \mathrm{mM})$ and TS (7.5 mM) upon increasing concentrations of resveratrol, (B) Reaction between the hydroxyl radical and resveratrol.

Author Contributions: G.M.R.-M. performed the experiments and M.A.M. and M.L.M. designed the experiments and wrote the manuscript.

Funding: This research was funded by Spanish Government (Grant SEV-2016-0683) and Generalitat Valenciana (Prometeo Program).

Conflicts of Interest: The authors declare no conflict of interest.

\section{References}

1. Nathan, C.; Ding, A. SnapShot: Reactive oxygen intermediates (ROI). Cell 2010, 140. [CrossRef] [PubMed]

2. Buettner, G.R. The pecking order of free radicals and antioxidants: Lipid peroxidation, alpha-tocopherol, and ascorbate. Arch. Biochem. Biophys. 1993, 300, 535-543. [CrossRef] [PubMed]

3. Treml, J.; Šmejkal, K. Flavonoids as potent scavengers of hydroxyl radicals. Compr. Rev. Food Sci. Food Saf. 2016, 15, 720-738. [CrossRef]

4. Rodriguez-Muñiz, G.M.; Gomis, J.; Arques, A.; Amat, A.M.; Marin, M.L.; Miranda, M.A. Hydroxyl radical as an unlikely key intermediate in the photodegradation of emerging pollutants. Photochem. Photobiol. 2014, 90, 1467-1469. [CrossRef] [PubMed]

5. Chen, J.; Pehkonen, S.O.; Lin, C.-J. Degradation of monomethylmercury chloride by hydroxyl radicals in simulated natural waters. Water Res. 2003, 37, 2496-2504. [CrossRef]

6. Halliwell, B.; Gutteridge, J.M.C. Free Radicals in Biology and Medicine, 4th ed.; Oxford University Press: Oxford, UK, 2007.

7. Finley, J.W.; Kong, A.-N.; Hintze, K.J.; Jeffery, E.H.; Ji, L.L.; Lei, X.G. Antioxidants in foods: State of the science important to the food industry. J. Agric. Food Chem. 2011, 59, 6837-6846. [CrossRef]

8. Krumova, K.; Cosa, G. Overview of reactive oxygen species. In Singlet Oxygen: Applications in Biosciences and Nanosciences, Volume 1; The Royal Society of Chemistry: London, UK, 2016; pp. 1-21.

9. Beal, M.F. Mitochondria, oxidative damage, and inflammation in Parkinson's disease. Ann. N. Y. Acad. Sci. 2003, 991, 120-131. [CrossRef]

10. Čolak, E. New markers of oxidative damage to macromolecules. J. Med. Biochem. 2008, 27, 1-16. [CrossRef]

11. Moreira, P.I.; Smith, M.A.; Zhu, X.; Honda, K.; Lee, H.G.; Aliev, G.; Perry, G. Oxidative damage and Alzheimer's disease: Are antioxidant therapies useful? Drug News Perspect. 2005, 18, 13-19.

12. Adadi, P.; Barakova, N.V.; Krivoshapkina, E.F. Selected methods of extracting carotenoids, characterization, and health concerns: A review. J. Agric. Food Chem. 2018, 66, 5925-5947. [CrossRef]

13. Huang, D.; Ou, B.; Prior, R.L. The chemistry behind antioxidant capacity assays. J. Agric. Food Chem. 2005, 53, 1841-1856. [CrossRef] [PubMed]

14. Moon, J.-K.; Shibamoto, T. Antioxidant assays for plant and food components. J. Agric. Food Chem. 2009, 57, 1655-1666. [CrossRef] [PubMed]

15. Sithisarn, P.; Carlsen, C.U.; Andersen, M.L.; Gritsanapan, W.; Skibsted, L.H. Antioxidative effects of leaves from Azadirachta species of different provenience. Food Chem. 2007, 104, 1539-1549. [CrossRef]

16. Song, L.-L.; Liang, R.; Li, D.-D.; Xing, Y.-D.; Han, R.-M.; Zhang, J.-P.; Skibsted, L.H. $\beta$-Carotene radical cation addition to green tea polyphenols. Mechanism of antioxidant antagonism in peroxidizing liposomes. J. Agric. Food Chem. 2011, 59, 12643-12651. [CrossRef] [PubMed]

17. Xu, M.; Jin, Z.; Ohm, J.-B.; Schwarz, P.; Rao, J.; Chen, B. Improvement of the antioxidative activity of soluble phenolic compounds in chickpea by germination. J. Agric. Food Chem. 2018, 66, 6179-6187. [CrossRef] [PubMed]

18. Yang, H.; Xue, X.; Li, H.; Apandi, S.N.; Tay-Chan, S.C.; Ong, S.P.; Tian, E.F. The relative antioxidant activity and steric structure of green tea catechins-A kinetic approach. Food Chem. 2018, 257, 399-405. [CrossRef] [PubMed] 
19. Yilmaz, Y.; Toledo, R.T. Major flavonoids in grape seeds and skins: Antioxidant capacity of catechin, epicatechin, and gallic acid. J. Agric. Food Chem. 2004, 52, 255-260. [CrossRef] [PubMed]

20. Renaud, S.; de Lorgeril, M. Wine, alcohol, platelets, and the French paradox for coronary heart disease. Lancet 1992, 339, 1523-1526. [CrossRef]

21. Kanner, J.; Frankel, E.; Granit, R.; German, B.; Kinsella, J.E. Natural antioxidants in grapes and wines. J. Agric. Food Chem. 1994, 42, 64-69. [CrossRef]

22. MacDonald-Wicks, L.K.; Wood, L.G.; Garg, M.L. Methodology for the determination of biological antioxidant capacity in vitro: A review. J. Sci. Food Agric. 2006, 86, 2046-2056. [CrossRef]

23. Niki, E.; Noguchi, N. Evaluation of antioxidant capacity. What capacity is being measured by which method? IUBMB Life 2000, 50, 323-329. [CrossRef] [PubMed]

24. DeMatteo, M.P.; Poole, J.S.; Shi, X.; Sachdeva, R.; Hatcher, P.G.; Hadad, C.M.; Platz, M.S. On the electrophilicity of hydroxyl radical: A laser flash photolysis and computational study. J. Am. Chem. Soc. 2005, 127, 7094-7109. [CrossRef] [PubMed]

25. Poole, J.S.; Shi, X.; Hadad, C.M.; Platz, M.S. Reaction of hydroxyl radical with aromatic hydrocarbons in nonaqueous solutions: A laser flash photolysis study in acetonitrile. J. Phys. Chem. A 2005, 109, 2547-2551. [CrossRef]

26. Marin, M.L.; Lhiaubet-Vallet, V.; Santos-Juanes, L.; Soler, J.; Gomis, J.; Argues, A.; Miranda, M.A. A photophysical approach to investigate the photooxidation mechanism of pesticides: Hydroxyl radical versus electron transfer. Appl. Catal. B 2011, 103, 48-53. [CrossRef]

27. Rodríguez-Muñiz, G.M.; Marin, M.L.; Lhiaubet-Vallet, V.; Miranda, M.A. Reactivity of nucleosides with a hydroxyl radical in non-aqueous medium. Chem. Eur. J. 2012, 18, 8024-8027. [CrossRef]

28. Mitroka, S.; Zimmeck, S.; Troya, D.; Tanko, J.M. How solvent modulates hydroxyl radical reactivity in hydrogen atom abstractions. J. Am. Chem. Soc. 2010, 132, 2907-2913. [CrossRef] [PubMed]

29. Serafini, M.; Maiani, G.; Ferro-Luzzi, A. Alcohol-free red wine enhances plasma antioxidant capacity in humans. J. Nutr. 1998, 128, 1003-1007. [CrossRef]

30. Arnous, A.; Makris, D.P.; Kefalas, P. Effect of principal polyphenolic components in relation to antioxidant characteristics of aged red wines. J. Agric. Food Chem. 2001, 49, 5736-5742. [CrossRef]

31. Frankel, E.N.; Kanner, J.; German, J.B.; Parks, E.; Kinsella, J.E. Inhibition of oxidation of human low-density lipoprotein by phenolic substances in red wine. Lancet 1993, 341, 454-457. [CrossRef]

32. Ghiselli, A.; Nardini, M.; Baldi, A.; Scaccini, C. Antioxidant activity of different phenolic fractions separated from an Italian red wine. J. Agric. Food Chem. 1998, 46, 361-367. [CrossRef] [PubMed]

33. Rice-Evans, C. Flavonoid antioxidants. Curr. Med. Chem. 2001, 8, 797-807. [CrossRef] [PubMed]

34. Wadsworth, T.L.; Koop, D.R. Effects of the wine polyphenolics quercetin and resveratrol on pro-inflammatory cytokine expression in RAW 264.7 macrophages. Biochem. Pharmacol. 1999, 57, 941-949. [CrossRef]

35. Paceasciak, C.R.; Hahn, S.; Diamandis, E.P.; Soleas, G.; Goldberg, D.M. The red wine phenolics trans-resveratrol and quercetin block human platelet aggregation and eicosanoid synthesis: Implications for protection against coronary heart disease. Clin. Chim. Acta 1995, 235, 207-219. [CrossRef]

36. Schneider, Y.; Vincent, F.; Duranton, B.; Badolo, L.; Gosse, F.; Bergmann, C.; Raul, F. Anti-proliferative effect of resveratrol, a natural component of grapes and wine, on human colonic cancer cells. Cancer Lett. 2000, 158, 85-91. [CrossRef]

37. Li, D.D.; Han, R.M.; Liang, R.; Chen, C.H.; Lai, W.Z.; Zhang, J.P.; Skibsted, L.H. Hydroxyl radical reaction with trans-resveratrol: Initial carbon radical adduct formation followed by rearrangement to phenoxyl radical. J. Phys. Chem. B 2012, 116, 7154-7161. [CrossRef] [PubMed]

Sample Availability: Samples of the compounds are not available from the authors. 